\title{
Peru: Managers must monitor quality of care regularly
}

Frontiers in Reproductive Health

Follow this and additional works at: https://knowledgecommons.popcouncil.org/departments_sbsr-rh

Part of the International Public Health Commons, Quality Improvement Commons, and the Women's Health Commons

How does access to this work benefit you? Let us know!

\section{Recommended Citation}

"Peru: Managers must monitor quality of care regularly," FRONTIERS OR Summary. Washington, DC: Population Council, 2000. 


\section{Peru Quality of Care}

OR Summary 6

\section{Managers Must Monitor Quality of Care Regularly}

\begin{abstract}
Family planning providers at Peru's government health facilities conform to national care guidelines in that more than 90 percent of them treat their clients respectfully and offer them a wide choice of contraceptive options. Nevertheless, the majority of providers could further improve the quality of care by giving clients more information about correct use and possible side effects of their chosen method and by screening for contraindications. A 100 percent quality standard ought to be established to avoid violation of individual reproductive rights.
\end{abstract}

\section{Background}

In the late 1980s, Peru's National Family Planning Program within the Ministry of Health $(\mathrm{MOH})$ assigned method-specific targets to clusters of health facilities. In 1998 the $\mathrm{MOH}$ changed its policies to ensure that services responded to individual reproductive health needs and wishes. It eliminated method quotas, ended voluntary surgical contraception (VSC) campaigns, and issued norms to ensure quality of care and informed choice.

In 1999 the Population Council collaborated with the $\mathrm{MOH}$ to determine whether providers were complying with the new guidelines and, secondarily, to develop a monitoring system to assess compliance over time.

\section{Findings}

- More than 90 percent of MOH family planning providers treat their clients with respect and provide a variety of contraceptive options without showing bias for or against any particular method.
- Nevertheless, MOH providers can do more to ensure that every client receives adequate information about her/his chosen method. For example, most providers warned simulated clients about possible menstrual changes associated with the injectable DMPA, but they did not mention possible delayed conception after discontinuation. Actual clients in exit interviews showed adequate general knowledge about the pill, condom, injectable and VSC. However, specific knowledge concerning the method chosen or used was incomplete.

- Most providers in urban health centers did not check simulated clients for three of the four medical conditions that are contraindicated for DMPA use. Few of the providers in health centers gave information on danger signs requiring medical attention.

More than 90 percent of clients who had been sterilized in hospitals stated that they had made the decision themselves or jointly with the provider and 98 percent knew its reproductive consequences. 
- In urban health centers, simulated clients were counseled for 2 to 45 minutes.

Providers conveyed 43 percent more information in the 9 to 14-minute sessions compared with 2 to 8 -minute sessions.

- In home interviews, most clients at rural health posts stated that they had made the decision to use contraception, and many had selected a specific method prior to visiting the health post. Rural clients, however, had limited knowledge about their chosen method.

\section{Policy Implications}

- The MOH has produced and circulated new quality of care norms and strengthened its provider retraining efforts and supervision strategies.
$\mathrm{MOH}$ facilities and individual providers should be evaluated on the quality of their performance and should receive regular feedback.

- Providers should invest as much time as needed in interactions with clients.

- A 100 percent quality standard must be established to avoid violations of individual reproductive rights.

- Two of the five data collection modes - the client exit interview and the use of simulated clients requesting DMPA - proved reliable for monitoring the quality of care in health centers. Monitoring tools for hospitals and rural health posts need further improvement.

February 2000

\section{Study Design}

In order to conserve time and funds, the study used Lot Quality Assurance Sampling to draw a sample of Peru's 6,589 service delivery points. The study sample consisted of 19 hospitals, 19 health centers, and 19 health posts. Six observations were obtained in each facility. Data were collected from June through August 1999 as follows:

- Hospitals were assessed using reports of simulated clients who requested VSC counseling and home interviews with VSC adopters.

- Health centers were assessed using reports from simulated clients who requested the injectable DMPA and exit interviews with family planning clients.

- Rural health posts were assessed through home interviews with clients who had recently started using family planning.

For an element to meet the LQAS standard, at least 95 percent of the six clients interviewed at each facility had to receive specific information or a specific service from the provider in at least 80 percent of the facilities sampled. Parallel analyses were made on the basis of 95 percent confidence intervals in each sample $(\mathrm{N}=114)$.

León, Federico R., 1999. Peru: Providers' Compliance with Quality of Care Norms.

León, Federico R. et al., 1999. Counseling Sessions Length and Amount of Information Exchange in Peruvian Clinics. For more information, contact: Population Council, Av. San Borja Sur 676, Lima 43, Peru. Tel. 511-475-0275; Fax: 511-475-0675; E-mail: pclima@amauta.rcp.net.pe or contact: Population Council, Escondida 110, Villa Coyoacán, 04000, Mexico, D.F. Mexico. Tel. 52-56598537; Fax: 52-5554-1226; E-mail: disemina@popcouncil.org.mx.

This project was conducted with support from the U.S. AGENCY FOR INTERNATIONAL DEVELOPMENT, Office of Population, under Cooperative Agreement Number HRN-A-00-98-00012-00.

12 Population Council 